\title{
Change in manuscript categories for Journal of Medical Ultrasonics
}

\section{Yoshiki Hirooka $^{1}$}

(c) The Japan Society of Ultrasonics in Medicine 2019

To our members,

We recently changed the manuscript categories for our English-language Journal of Medical Ultrasonics.

We have stopped taking Case Report and Technical Note submissions, and we have added a new category called Images.

Please prepare submissions of Images according to the Journal of Medical Ultrasonics' Instructions for Authors provided below.

We look forward to receiving your submissions.

Instructions for Authors
Images: Ultrasonographic images that illustrate important findings of special interest on a particular subject or a case study. Images may be published at the discretion of the editor. The maximum number of authors should be seven (7). Articles should have the following format: (1) title page, (2) text (maximum 400 words), (3) references (maximum five), (4) figure (maximum one, which may contain more than one element), and (5) figure caption.

Yoshiki Hirooka, Editor-in-Chief The Japan Society of Ultrasonics in Medicine

Yoshiki Hirooka

editorialoffice@jsum.or.jp

1 The Japan Society of Ultrasonics in Medicine, Chiyoda, Japan 